\title{
FUNKCINIŲ JUDESIŲ POVEIKIS ASMENŲ, KURIE JAUČIA LĖTINI NESPECIFINI APATINĖS NUGAROS DALIES SKAUSMĄ, FUNKCINIO LIEMENS PAJĖGUMO IR JUDESIO BAIMÉS RODIKLIAMS
}

\author{
Inga Muntianaité丶 ${ }^{1}$, Daina Verbickaité丶 \\ Jurga Indriūniené $\dot{e}^{1}$, Ieva Eglè Jamontaitè ${ }^{1}$ \\ ${ }^{1}$ Vilniaus universitetas, Medicinos fakultetas
}

\section{SANTRAUKA}

Tyrimo pagrindimas. Žmonėms, kurie skundžiasi lètiniu apatinès nugaros dalies skausmu atlikdami fizines veiklas, būdinga didesnè judèjimo baimè, jie jautresni skausmui bei nerimauja, kad skausmas pasikartos. Funkcinius judesius jie atlieka lèčiau nei sveiki asmenys.

Tikslas - nustatyti funkcinių judesių poveikị žmonių, kurie jaučia lètinį nespecifinį apatinès nugaros dalies skausmą, funkcinio liemens pajègumo, funkcinès negalios ir judesio baimès rodikliams.

Metodai. Tyrime dalyvavo 34 tiriamieji, kurie jaute lètini nespecifini apatinès nugaros dalies skausmą. Buvo vertinama tiriamujų skausmo intensyvumas, negalia, judesio baimè ir funkcinis liemens pajėgumas. Po tyrimo tiriamieji atsitiktine tvarka buvo suskirstyti ị dvi grupes: kontrolinę $(n=$ 17), kuriai buvo taikoma kineziterapijos pratimų programa liemens, dubens ir kojų tarpraumeninei koordinacijai gerinti ir tiriamają $(n=17)$, kuri atliko tą pačią kineziterapijos programą ir papildomus funkcinius judesius.

Rezultatai. Analizuojant tiriamųjų rezultatus prieš tyrimą ir po jo, gautas reikšmingas visų rodiklių pagerejjimas. Skausmo intensyvumas sumažejo abiejose grupèse $(p<0,05)$, tačiau nesiskyrè palyginus tarp grupių ( $p>0,05)$. Vertinant judesio baimę, nustatyta, kad tiriamosios grupės tiriamujų kineziofobijos lygis sumažejo reikšmingai labiau nei kontrolinès grupès $(p<0,05)$. Analizuojant Funkcinès negalios klausimyno duomenis paaiškejjo, kad abiejose grupėse funkcinė negalia sumažèjo vidutiniškai $4 \pm 3,1$ balo $(p<0,05)$. Tiriamosios grupès rezultatai statistiškai reikšmingai geresni nei kontrolinès, ịvertinus funkcinị liemens pajègumą testuose „Sėstis-stotis“ ir „Lenktis-tiestis“ $(p<0,05)$.

Išvados. Funkciniai pratimai taikomi kartu su pratimais, kurie gerina liemens, dubens ir kojų tarpraumeninę koordinaciją, sumažina judesio baimę bei pagerina kai kurių funkcinių judesių atlikimą geriau nei taikant vien tik liemens, dubens ir kojų tarpraumeninę koordinaciją gerinančius pratimus asmenims, kurie jaučia lètinị nespecifinị apatinès nugaros dalies skausmą.

Raktažodžiai: funkciniai judesiai, judesio baimé, apatinis nugaros skausmas.

\section{IVADAS}

Lètinis nespecifinis apatinès nugaros dalies skausmas (ANDS) - tai viena dažniausių priežasčių, kuri didina asmenų funkcinę negalią, neigiamai veikia jų gyve-

Copyright (C) 2021 Inga Muntianaitė, Daina Verbickaitė, Jurga Indriūnienė, Ieva Eglè Jamontaitė. Published by Lithuanian Sports University.

This is an Open Access article distributed under the terms of the Creative Commons Attribution 4.0 International License, which permits unrestricted use, distribution, and reproduction in any medium, provided the original author and source are credited. 
Funkcinių judesių poveikis asmenų, kurie jaučia lètinị nespecifinị apatinès nugaros dalies skausmą, funkcinio liemens pajègumo ir judesio baimès rodikliams

nimo kokybę, dèl to kasmet didèja bendras nedarbingumo dienų skaičius, mažeja bendras fizinio aktyvumo lygis. Pastaruoju metu ši kaulų ir raumenų sistemos problema, kuri sukelia nuolatinị ir (arba) pasikartojantị skausmą ir negalią, nelaikoma tik stuburo juosmeninès dalies anatominiu, struktūriniu arba biomechaniniu sutrikimu (O'Sullivan et al., 2018). Tyrimų duomenimis, lètinis nespecifinis apatinès nugaros dalies skausmas kyla dèl ịvairių kompleksinių biopsichosocialinių veiksnių sąveikos (Synnott et al., 2016; Silva, Martins, 2014). Tai ne tik struktūriniai arba biomechaniniai, bet ir kognityviniai (asmens įsitikinimai ir požiūris, skausmo sureikšminimas ir jo ịveikimo būdai), psichologiniai (baimè, depresija, nerimas), socialiniai (šeimos ir darbo problemos) veiksniai (Synnott et al., 2016; Tousignant-Laflamme et al., 2017). Užsienio autoriai teigia, kad pacientai, kurie skundžiasi lètiniu apatinès nugaros dalies skausmu atlikdami fizines veiklas, pasižymi didesne judesių arba judejjimo baime, yra jautresni skausmui bei nerimauja, kad skausmas pasikartos (Carvalho et al., 2017; Wertli et al., 2017). Pastebetta, kad kasdienių judesių atlikimo vengimas dèl baimès susižeisti ir (arba) iššaukti didesnị skausmą ilgainiui sąlygoja šiu pacientų fizinio aktyvumo sumažèjimą ir skausmo kartojimąsi (Tousignant-Laflammeet al., 2017).

Tyrimo tikslas - nustatyti funkcinių judesių poveikị pacientų, kurie jaučia lètini nespecifini apatinès nugaros dalies skausmą, funkcinio liemens pajėgumo, funkcinès negalios ir judesio baimès rodikliams.

\section{METODAI}

Tyrimas buvo atliktas asmens sveikatos priežiūros įstaigoje. I tyrimą buvo itraukti asmenys, kurie atitinka šiuos įtraukimo kriterijus: amžius nuo 30 iki 62 metų, lètinis nespecifinis ANDS (tęsiasi ilgiau nei 3 mèn.), ANDS didesnis nei 3 balai (pagal skaičiu analoginę skalę), mažiausiai vidutinio sunkumo negalia (5 ir daugiau balų pagal Roland-Morris funkcinès negalios klausimyną). Neįtraukimo ị tyrimą kriterijai: skausmas, plintantis ị koją; ūminis ANDS (trunkantis iki 1 mèn.), liemens, dubens srities trauma per pastaruosius 3 mèn., mažiau nei prieš dvejus metus taikytas chirurginis gydymas, specifinè stuburo patologija (piktybiniai navikai, infekcija, sąnarių arba kaulų uždegiminès ligos), bet kokie vestibiulinio aparato, regos arba neurologiniai sutrikimai, kurie turi įtakos pusiausvyrai; negebejjimas atlikti bet kokias funkcines užduotis be pagalbinių priemonių, negebejjimas skaityti ir suprasti rašytinius lietuvių kalbos dokumentus bei vadovautis žodinėmis instrukcijomis lietuvių kalba.

Tyrime dalyvavo 38 tiriamieji (30 moterų ir 8 vyrai), kurių amžiaus vidurkis $45,6 \pm 10,0$ metai. Keturi tiriamieji tyrimo nebaigè. 
Visi tiriamieji $(\mathrm{n}=34)$ buvo supažindinti su tyrimo tikslais, tyrimo testavimo procedūromis, tyrimo nauda ir galimais nepatogumais. Atlikus pirmaji asmenų tyrimą, tiriamieji atsitiktine tvarka buvo suskirstyti ị dvi grupes: kontrolinę ir tiriamają. Kontrolinę grupę sudare 17 asmenų ( 5 vyrai ir 12 moteru), tiriamają 17 (3 vyrai ir 14 moterų). Grupès pagal tiriamujų lytį, amžių ir skausmo intensyvumo rodiklius prieš tyrimą buvo homogeniškos ir tarpusavyje nesiskyrè $(p>$ $0,05)$. Kontrolinei grupei buvo taikoma kineziterapijos pratimų programa liemens, dubens ir kojų tarpraumeninei koordinacijai gerinti, o tiriamajai - kineziterapijos pratimų programa liemens, dubens ir kojų tarpraumeninei koordinacijai gerinti bei funkcinių pratimų seka. Po 10 kineziterapijos užsiemimų buvo atliktas antras tyrimas.

Kontrolinei ir tiriamajai grupei dvi savaites, kiekvieną darbo dieną, buvo taikoma kineziterapija, kurią sudarè pramankšta, liemens, dubens raumenu jègos ištvermès, koordinacijos pratimai, kojų, sėdmenų ir nugaros raumenų tempimo pratimai. Visi aktyvūs pratimai buvo atliekami po tris serijas, 10-12 pakartojimų, atliekant statinio tempimo pratimus padètis buvo išlaikoma 20 sek. Tiriamoji grupé papildomai 10 min. atliko funkcinių judesių seką, kurios tikslai buvo: išmokyti taisyklingai atlikti funkcinius judesius, pagerinti neuroraumeninę kontrolę ir funkcinę būklę bei sumažinti funkcinių judesių atlikimo baimę. Pirmi užsièmimai, kuriuos atliko pacientai: $360^{\circ}$ apsivertimas pagal dinaminị neuroraumeninès stabilizacijos metodą (Hoogenboom, Voight, 2015); atsisėdimas ant kèdès imituojant pritūpimą; pasilenkimas laikant lazdą už nugaros išilgai stuburo; kojų kèlimas pakaitomis iki klubų aukščio (imituojant lipimą laiptais) ir atsisėdimas-atsistojimas nuo kẻdès. Kiekvienas funkcinis pratimas buvo atliekamas po tris serijas, 10-12 pakartojimu. Nuo penkto užsièmimo pasilenkimai buvo atliekami be pagalbinès priemonès. Visus užsièmimus vedè kineziterapeutas.

Buvo taikyti šie tyrimo metodai:

Skaičių analoginè skalè nuo 0 iki 10 balu (SAS) - skausmo intensyvumui ịvertinti.

Modifikuotas judesių baimès vertinimo klausimynas (TSK) (angl. Tampa scale of kinesiophobia) - judesio arba pasikartojančio susižeidimo baimès lygiui nustatyti (Miller et al., 1991). Klausimyną sudarè 17 teiginių, susijusių su skausmu ir tiriamojo funkcine būkle. Suminis balų skaičius - 17-68, pastarasis nurodo, kiek tiriamojo judejjimą riboja baimė patirti skausmą arba pakartotinai susižeisti. Kuo didesnis TKS ịvertis, tuo kineziofobijos lygis aukštesnis.

Roland-Morris (RM) funkcinès negalios ịvertinimo klausimynas - subjektyvus tiriamujų ANDS funkcinio pajègumo ịvertinimas. Maksimalus galimas balų skaičius - 24, rodo žymią funkcinę negalią. Mažesnė balų suma reiškia mažesnę nugaros skausmo ịtaką funkcinei asmens būklei (Roland, Morris, 1983). 
Funkcinių judesių poveikis asmenų, kurie jaučia lètinị nespecifinị apatinès nugaros dalies skausmą, funkcinio liemens pajègumo ir judesio baimès rodikliams

Liemens funkcinis pajëgumas buvo vertinamas: Stotis-sėstis (sek.), Lenktistiestis (sek.), $360^{\circ}$ apsivertimo (gulint) (sek.), funkcinio siekimo testais $(\mathrm{cm})(\mathrm{Sim}-$ monds et al., 1998). Prieš vertinant funkcinį liemens pajègumą, tiriamieji išklause žodines teste naudojamu judesių atlikimo instrukcijas ir atliko tris bandymus, iš kurių: pirmasis - pabandymas, antrasis ir trečiasis - testavimai, jų rezultatų vidutinè reikšmè - galutinis rezultatas.

Matematinè statistika. Tyrimo metu gauti rezultatai apdoroti „Windows Microsoft Excel 2016“ bei „R Commander i386 3.4.0“ kompiuterinemis programomis. Tolydiesiems kintamiesiems vertinti buvo apskaičiuojami aritmetiniai vidurkiai ir standartiniai nuokrypiai (SN) pasirinkus 95 proc. pasikliautinaji intervalą. Hipotezei apie kintamojo skirstinio normalumą tikrinti naudotas Shapiro'o-Wilk'o testas. Dviejų priklausomų imčių palyginimui naudotas porinis Student'o (t) kriterijus arba neparametrinis porinis Wilcoxon'o kriterijus, o dviejų nepriklausomų imčiu palyginimui - Stjudento (t) testas arba neparametrinis Mann'o-Whitney'aus kriterijus. Duomenų skirtumas statistiškai reikšmingas ir patikimas, kai $\mathrm{p}<0,05$.

\section{TYRIMO REZULTATAI}

Lètinis apatinès nugaros dalies skausmas statistiškai reikšmingai sumažèjo abiejose grupèse: kontrolinėje grupeje $1 \pm 0,9$ balo $(\mathrm{p}<0,05)$, tiriamojoje grupèje $2,5 \pm 1,9$ balo $(\mathrm{p}<0,05)$. Tarp grupių statistiškai reikšmingo skirtumo nebuvo (1 lentelè).

Judesio baimès rodikliai po kineziterapijos statistiškai reikšmingai sumažèjo abiejose grupèse. Kontrolinès grupès vidutinis judesio baimès lygis sumažèjo $2,8 \pm 2,3$ balo $(\mathrm{p}<0,05)$, o tiriamojoje grupeje sumažejo $8,2 \pm 5,1$ balo $(\mathrm{p}<0,05)$. Po kineziterapijos tiriamosios grupès judesio baimès lygis sumažejo reikšmingai daugiau nei kontrolinès grupès $(\mathrm{p}<0,05)$.

Išanalizavus modifikuoto RM klausimyno duomenis nustatyta, kad po 10 kineziterapijos užsièmimų kontrolinès grupès vidutinis funkcinės negalios įvertis sumažèjo $2,9 \pm 2,3$ balo $(p<0,05)$, tiriamosios grupès $-5,1 \pm 3,5$ balo $(\mathrm{p}<0,05)$. Tarp grupių statistiškai reikšmingo skirtumo nebuvo.

Liemens funkcinio pajègumo rodikliai pateikiami 2 lentelèje. Išanalizavus „Stotis-sèstis“ testo rezultatus, nustatyta, kad po kineziterapijos abiejų grupių rezultatas

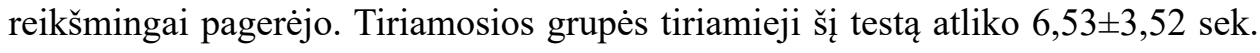
greičiau nei pirmo testavimo metu, kontrolinès grupès $-2,83 \pm 1,71$ sek. greičiau $(\mathrm{p}<0,05)$. Tiriamoji grupè atliko testą reikšmingai greičiau nei kontrolinè grupè.

Tiriamosios grupès testo „Lenktis-tiestis“ atlikimo reikšmių skirtumas prieš kineziterapiją ir po jos $-8,59 \pm 3,87$ sek, kontrolinès $-3,23 \pm 2,26$ sek. Šie skirtumai statistiškai reikšmingi. Testo atlikimo trukmè prieš kineziterapiją tarp grupių sta- 
tistiškai reikšmingai nesiskyrè, tačiau, apskaičiavus rezultatus po kineziterapijos, nustatytas statistiškai reikšmingas skirtumas tarp grupių - testo atlikimo laikas $(\mathrm{p}=0.0064)$.

1 lentelè. Tiriamųjų skausmo intensyvumo, judesio baimès ir funkcinès negalios rezultatai prieš ir po tyrimo

\begin{tabular}{|c|c|c|c|c|}
\hline $\begin{array}{c}\text { TYRIMO } \\
\text { METODAS }\end{array}$ & $\begin{array}{c}\text { Tyrimo atliki- } \\
\text { mas }\end{array}$ & $\begin{array}{c}\text { Tiriamoji } \\
\text { grupė }(\mathbf{n}=\mathbf{1 7}) \\
\bar{x} \pm \text { SN }\end{array}$ & $\begin{array}{c}\text { Kontrolinè } \\
\text { grupe } \\
(\mathbf{n}=\mathbf{1 7}) \\
\bar{x} \pm \mathbf{S N} \\
\end{array}$ & $\begin{array}{c}p \text { reikšmė } \\
\text { tarp grupių }\end{array}$ \\
\hline \multirow{3}{*}{$\begin{array}{l}\text { Skausmo intensy- } \\
\text { vumas, balai }\end{array}$} & Prieš KT & $5,2 \pm, 4$ & $4,8 \pm 1,1$ & $p>0,05$ \\
\hline & Po KT & $2,7 \pm 1,8$ & $3,8 \pm 1,6$ & $p>0,05$ \\
\hline & $\begin{array}{l}\text { p reikšmė } \\
\text { prieš ir po KT }\end{array}$ & 0.0001 & 0.0019 & \\
\hline \multirow{3}{*}{$\begin{array}{l}\text { Judesio baimé, } \\
\text { balai }\end{array}$} & Prieš KT & $44,1 \pm 6,2$ & $43,2 \pm 7,2$ & $p>0,05$ \\
\hline & Po KT & $35,9 \pm 3,8$ & $40,4 \pm 7$ & 0.0312 \\
\hline & \begin{tabular}{|l|}
$p$ reikšmė \\
prieš ir po KT
\end{tabular} & $3,66 \mathrm{e}^{-5}$ & $p=0,0005$ & \\
\hline \multirow{3}{*}{$\begin{array}{l}\text { Funkcinè negalia, } \\
\text { balai }\end{array}$} & Prieš KT & $9,9 \pm 5,5$ & $9,6 \pm 3.6$ & $p>0,05$ \\
\hline & Po KT & $4,9 \pm 4,5$ & $6,7 \pm 4$ & $p>0,05$ \\
\hline & $\begin{array}{l}p \text { reikšmė } \\
\text { prieš ir po KT }\end{array}$ & 0,0003 & 0,0004 & \\
\hline
\end{tabular}

Pastaba. KT - nineziterapija, $n$ - tiriamujų skaičius, $\bar{x}$ - vidurkis, $\mathrm{SN}$ - standartinis nuokrypis, $p$ - reikšmingumo lygmuo.

Po 10 kineziterapijos užsièmimų tiriamosios grupès tiriamieji apsivertimą per

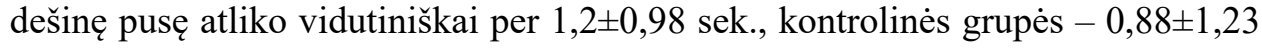
sek., reikšmingai greičiau. Atliekant apsivertimą per kairę pusę po 10 kineziterapijos užsièmimų tiriamosios ir kontrolinès grupès tiriamujų testo rezultatai reikšmin-

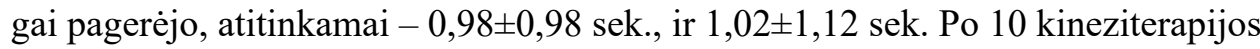
užsièmimų testų , $360^{\circ}$ apsivertimas kairèn“ ir , $360^{\circ}$ apsivertimas dešinėn“ atlikimo laikas tarp grupių statistiškai reikšmingai nesiskyrè. 
Funkcinių judesių poveikis asmenų, kurie jaučia lètinị nespecifinị apatinès nugaros dalies skausmą, funkcinio liemens pajègumo ir judesio baimès rodikliams

Išanalizavus Funkcinio siekimo testą, nustatyta, kad tiriamosios grupès rezultatai po kineziterapijos reikšmingai pagerèjo $6,3 \pm 2,1 \mathrm{~cm}$., kontrolinès grupès $4,9 \pm 4,1 \mathrm{~cm}(\mathrm{p}<0,05)$, tačiau tarp grupių nebuvo reikšmingo skirtumo.

2 lentelè. Tiriamųjų funkcinio liemens pajègumo testų rezultatai prieš ir po tyrimo

\begin{tabular}{|c|c|c|c|c|c|}
\hline \multicolumn{2}{|c|}{$\begin{array}{c}\text { TYRIMO } \\
\text { METODAS }\end{array}$} & \multirow{2}{*}{$\begin{array}{l}\begin{array}{c}\text { Tyrimo } \\
\text { atlikimas }\end{array} \\
\text { Prieš KT }\end{array}$} & \multirow[t]{2}{*}{$\begin{array}{c}\text { Tiriamosios } \\
\text { grupe } \\
(n=17) \\
\bar{x} \pm \mathrm{SN} \\
16,5 \pm 4,8\end{array}$} & \multirow{2}{*}{$\begin{array}{c}\begin{array}{c}\text { Kontrolinè } \\
\text { grupé } \\
(n=17) \\
\bar{x} \pm \mathrm{SN}\end{array} \\
15,5 \pm 4,8\end{array}$} & \multirow{2}{*}{\begin{tabular}{|l}
$\begin{array}{c}p \text { reikšmè } \\
\text { tarp grupių }\end{array}$ \\
0,5749
\end{tabular}} \\
\hline \multirow{15}{*}{ 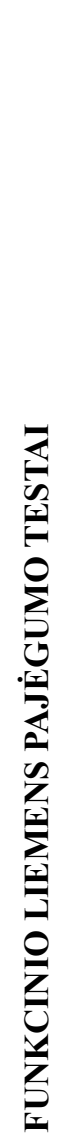 } & \multirow{3}{*}{$\begin{array}{l}\text { „Stotis- } \\
\text { séstis“6, } \\
\text { sek. }\end{array}$} & & & & \\
\hline & & Po KT & $9,9 \pm, 9$ & $12,7 \pm 3,9$ & \begin{tabular}{|l|}
0,0258 \\
\end{tabular} \\
\hline & & $\begin{array}{l}p \text { reikšmė prieš } \\
\text { ir po tyrimo }\end{array}$ & $9,887 \mathrm{e}^{-7}$ & $4,17 \mathrm{e}^{-6}$ & \\
\hline & \multirow{3}{*}{$\begin{array}{l}\text { „Lenktis- } \\
\text { tiestis“, } \\
\text { sek. }\end{array}$} & Prieš KT & $17,4 \pm 6,5$ & $16,7 \pm 5,7$ & 0,7472 \\
\hline & & Po KT & $8,8 \pm 3,4$ & $13,4 \pm 5,6$ & 0,0064 \\
\hline & & $\begin{array}{l}p \text { reikšmė prieš } \\
\text { ir po KT }\end{array}$ & $9,445 \mathrm{e}^{-8}$ & $2, \mathrm{e}^{-5}$ & \\
\hline & \multirow{3}{*}{$\begin{array}{l}\text { „,360 } \\
\text { apsiver- } \\
\text { timas“، } \\
\text { (gulint) } \\
\text { dešinèn, } \\
\text { sek. }\end{array}$} & Prieš KT & $3,8 \pm 1,5$ & $3,5 \pm 1,8$ & 0,2708 \\
\hline & & Po KT & $2,6 \pm 0,9$ & $2,6 \pm 0,8$ & 0,698 \\
\hline & & $\begin{array}{l}p \text { reikšmė prieš } \\
\text { ir po KT }\end{array}$ & 0.0001 & 0.0015 & \\
\hline & \multirow{3}{*}{$\begin{array}{l}, 360^{\circ} \\
\text { apsiver- } \\
\text { timas“، } \\
\text { (gulint) } \\
\text { kairèn, } \\
\text { sek. }\end{array}$} & Prieš KT & $3,6 \pm 1,4$ & $3,7 \pm 1,9$ & 0,7413 \\
\hline & & Po KT & $2,7 \pm 1,1$ & $2,6 \pm 1$ & 0,9715 \\
\hline & & $\begin{array}{l}p \text { reikšmė prieš } \\
\text { ir po KT }\end{array}$ & 0,0012 & 0,0010 & \\
\hline & \multirow{3}{*}{$\begin{array}{l}\text { Funkcinis } \\
\text { siekimo } \\
\text { testas, } \\
\mathrm{cm}\end{array}$} & Prieš KT & $23,9 \pm 10,7$ & $25,5 \pm 8,6$ & 0,6361 \\
\hline & & Po KT & $30,2 \pm 10,5$ & $30,4 \pm 9$ & 0,9444 \\
\hline & & $\begin{array}{l}p \text { reikšmė prieš } \\
\text { ir po KT }\end{array}$ & $1,206 \mathrm{e}^{-9}$ & 0,0001 & \\
\hline
\end{tabular}

Pastaba. $n$ - tiriamujų skaičius, $\bar{x}$ - vidurkis; $\mathrm{SN}$ - standartinis nuokrypis, $p$ - reikšmingumo lygmuo. 


\section{REZULTATŲ APTARIMAS}

Tyrime dalyvavę asmenys jautė vidutinio intensyvumo apatinės nugaros dalies skausmą pagal SAS. Po 10 kineziterapijos užsièmimų abiejose grupèse skausmas statistiškai reikšmingai sumažejo, tačiau tarp grupių skirtumo nebuvo.

Abiejų grupių tiriamujų TKS rodikliai buvo daugiau nei 40 balų. Vlaeyen set al. (1995) nurodo, kad didesnis nei 37 balų rodiklis rodo didelę judesio baimę. Pasak Pitchai et al. (2017), yra tiesioginis ryšys tarp skausmo ir kineziofobijos lygio asmenų, kurie jaučia lètini ANDS. Be to, aukštesnis judesio baimès lygis didina funkcinès negalios tikimybę, o tai žymiai pablogina gyvenimo kokybę (Pitchai et al., 2017). Šio tyrimo duomenimis, vidutinis tiriamujų judesio baimès lygis po 10 kineziterapijos užsièmimų sumažèjo 5,5 4,7 balo. Be to, palyginus grupes tarpusavyje, pastebèta, kad tiriamojoje grupejje asmenų kineziofobijos lygis sumažèjo reikšmingai daugiau nei kad kontrolinèje grupeje $(\mathrm{p}<0,05)$. Svarbu tai, jog tiriamosios grupès kineziofobijos rodiklis sumažèjo $8,2 \pm 5,1$ balo, o tai, anot Bergsten et al. (2012), rodo ir galimą funkcinio pajègumo padidejjimą. Šis autorius teigia, kad mažiausias kliniškai reikšmingas TKS pokytis yra 8 balai (Bergsten et al., 2012). Tiriamosios grupès tiriamieji atliko ịprastus kasdienèje veikloje funkcinius pratimus, kurie, kaip rodo rezultatai, sumažino judejjimo baimę. Pagal modifikuoto RM klausimyno rezultatus apskaičiuota, jog vidutinis tiriamųų funkcinès negalios lygis sumažèjo 4 balais. Atlikta publikuotų tyrimų metaanalizė parodè, kad 2-3 balų pokytis gali būti laikomas minimaliu kliniškai reikšmingu pokyčiu (Bombardier et al., 2001). Remiantis pastarujų tyrimų išvadomis, judesio baimè (Altug et al., 2016) ir (arba) funkcinè negalia (Leysen et al., 2017) yra glaudžiai susijusios su pacientų, patiriančių lètinị ANDS, ligos suvokimu, todèl pirminiame paciento tyrime svarbu įvertinti paciento ligos suvokimą, o ị gydymo programą įtraukti edukacinį komponentą ir laipsnišką pratimų progresiją iki funkcinių užduočių (Tousignant-Laflamme et al., 2017; Schiltenwolf et al., 2017).

2015 m. sisteminèje apžvalgoje ir metaanalizèje A. Searl et al. nustatè, kad, sergant lètiniu nespecifiniu ANDS, sumažèja funkcinis pajègumas. Buvo vertinta kasdienių funkcinių veiklų, kurioms būtina apatinè nugaros dalis, atlikimo trukmè ir santykinis intensyvumas. Tyrimo rezultatai parodè, jog nugaros skausmą jaučiantys asmenys užduotis atlieka lèčiau nei sveikieji. P. Parreira et al. (2015) apklausė 679 pacientus, kurie jautè lètinị nespecifinį ANDS, jų amžiaus vidurkis buvo $44,7 \pm 13,8$ metai, nugaros skausmo intensyvumas $-5,3 \pm 2,1$ balo pagal SAS ir nustatè, jog labiausiai nugaros skausmą sustiprina daiktų kèlimas, stovejjimas ir sèdejimas, namų ruošos ir profesijos darbų atlikimas.

Šiame tyrime funkciniam liemens pajègumui ịvertinti buvo naudojamos keturios funkcinès standartizuotos užduotys. Tyrimo duomenimis, funkcinis pajègu- 
Funkcinių judesių poveikis asmenų, kurie jaučia lètinị nespecifinị apatinès nugaros dalies skausmą, funkcinio liemens pajègumo ir judesio baimès rodikliams

mas reikšmingai pagerèjo abiejose grupėse. Palyginus grupes tarpusavyje, tiriamosios grupès tiriamieji testą „Sėstis-stotis“ atliko 2,8 $\pm 5,3$ sek., o „Lenktis-tiestis“ $4,7 \pm 7,0$ sek., greičiau nei kontrolinès grupès tiriamieji $(\mathrm{p}<0,05)$. J. Cortell-Tormas et al. (2017) tyrimo duomenimis, periodinis funkcinis treniravimas reikšmingai sumažina nugaros skausmą, negalią, pagerina funkcinę būklę bei gyvenimo kokybę, palyginus su tradicine stabilizavimo pratimų programa.

\section{IŠVADOS}

Funkciniai pratimai, kurie taikomi kartu su liemens, dubens ir kojų tarpraumeninę koordinaciją gerinančiais pratimais, sumažina judesio baimę bei pagerina kai kurių funkcinių judesių atlikimą geriau nei taikant tik liemens, dubens ir kojų tarpraumeninę koordinaciją gerinančius pratimus asmenims, kurie jaučia lètinị nespecifinị apatinès nugaros dalies skausmą.

\section{LITERATŪRA}

Altug, F., Una,1 A., Kilavuz, G., et al. (2016). Investigation of the relationship between kinesiophobia, physical activity level and quality of life in patients with chronic low back pain. Journal of Back and Musculoskeletal Rehabilitation, 29 (3), 527-531.

Bergsten, C., Lundberg, M., Lindberg, P., et al. (2012). Change in kinesiophobia and its relation to activity limitation after multidisciplinary rehabilitation in patients with chronic back pain. Disability and Rehabilitation, 34 (10), 852-858.

Bombardier, C., Hayden, J., Beaton, D. E. (2001) Minimal clinically important difference. Low back pain: outcome measures. J Rheumatol, 28 (2), 431-438.

Carvalho, A., Bertor, W., Abico, R., et al. (2017). Nonspecific chronic low back pain and incapacity level: influence of walking performance. Revista Dor, 18 (2), 150-155.

Cortell-Tormo, J., Sánchez, P., Chulvi-Medrano, I., et al. (2017). Effects of functional resistance training on fitness and quality of Life in females with chronic nonspecific low-back pain. Journal of Back and Musculoskeletal Rehabilitation, 31 (1), 95-105.

Hoogenboom, B. J., \& Voight, M. L. (2015). Rolling revisited: using rolling to assess and treat neuromuscular control and coordination of the core and extremities of athletes. International Journal of Sports Physical Therapy, 10 (6), 787-802.

Leysen, M., Nijs, J., Van Wilgen, C., et al. (2017). Illness Perceptions Explain the Variance in Functional Disability, but Not Habitual Physical Activity, in Patients With Chronic Low Back Pain: A Cross-Sectional Study. Pain Practice, 18 (4), 523-531.

Miller, R. P., Kori, S., Todd, D. (1991). The Tampa Scale: a measure of kinesiophobia. Clin J Pain, 7 (1), 51-52.

O’Sullivan, P., Caneiro, J., O'Keeffe, M., et al. (2018). Cognitive Functional Therapy: An Integrated Behavioral Approach for the Targeted Management of Disabling Low Back Pain. Physical Therapy, 98 (5), 408-423.

Parreira, P., Ferreira, M., Latimer, J., et al. (2015). Can patients identify what triggers their back pain? Secondary analysis of a case-crossover study. Physiotherapy, 156 (10), 1913-1919.

Pitchai, P., Chauhan, S., \& Sreeraj, S. (2017). Impact of kinesiophobia on quality of life in subjects with low back pain: a cross-sectional study. International Journal of Physiotherapy and Research, 5 (4), 2232-2239.

Roland, M. O. \& Morris, R. W. (1983). A study of the natural history of back pain. Part 1: Development of a reliable and sensitive measure of disability in low back pain. Spine, 8 (2), 141-14.

Schiltenwolf, M., Akbar, M., Neubauer, E., et al. (2017). The cognitive impact of chronic low back pain: Positive effect of multidisciplinary pain therapy. Scandinavian Journal of Pain, 17 (1), 273-278. 
Inga Muntianaite, Daina Verbickaitė, Jurga Indriūnienė, Ieva Eglè Jamontaitė

Searle, A., Spink, M., Ho A., \& Chuter, V. (2015). Exercise interventions for the treatment of chronic low back pain: a systematic review and meta-analysis of randomised controlled trials. Clinical Rehabilitation, 29 (12), $1155-1167$

Silva, A. \& Martins, M. (2014). Pain, kinesiophobia and quality of life of low back pain patients. Revista Dor, $15(2), 117-120$.

Simmonds, M. J., Olson, S., Jones, S., et al. (1998). Psychometric Characteristics and Clinical Usefulness of Physical Performance Tests in Patients With Low Back Pain. Spine, 23 (22), 2412-2421.

Synnott, A., O'Keeffe, M., Bunzli, S., et al. (2016). Physiotherapists report improved understanding of and attitude toward the cognitive, psychological and social dimensions of chronic low back pain after Cognitive Functional Therapy training: a qualitative study. Journal of Physiotherapy, 62 (4), 215-221.

Tousignant-Laflamme, Y., Martel, M., Joshi, A., et al. (2017). Rehabilitation management of low back pain - it‘s time to pull it all together! Journal of Pain Research, 10, 2373-2385.

Vlaeyen, J. W., Kole-Snijders, A. M., Boeren, R. G., et al. (1995). Fear of movement/(re)injury in chronic low back pain and its relation to behavioral performance. Pain, 62 (3), 363-372.

Wertli, M., Held, U., Lis, A., Campello, M., et al. (2017). Both positive and negative beliefs are important in patients with spine pain: findings from the Occupational and Industrial Orthopaedic Center registry. The Spine Journal, 18 (8), 1463-1474

\title{
EFFECT OF FUNCTIONAL MOVEMENTS ON TRUNK FUNCTIONAL CAPACITY AND KINESIOPHOBIA IN PATIENTS WITH CHRONIC NONSPECIFIC LOW BACK PAIN
}

\author{
Inga Muntianaité1, Daina Verbickaité丶 \\ Jurga Indriūniené $\dot{1}^{1}$, Ieva Eglè Jamontaité ${ }^{1}$ \\ ${ }^{1}$ Faculty of Medicine of Vilnius University
}

\section{ABSTRACT}

Background. People with chronic low back pain have more fear of movements during physical activities and are more sensitive to pain as well as are anxious that it will recur. They perform functional movements slower than healthy individuals.

Aim. To determine the effect of functional movements on the indicators of trunk functional capacity, functional disability and fear of movement in people experiencing chronic non-specific low back pain.

Methods. Patients with chronic nonspecific low back pain $(n=34)$ participated in the study. Pain intensity, disability, fear of movement, and trunk functional capacity were assessed. Participants were randomly assigned to control group $(n=17)$ and subject group $(n=17)$. The control group underwent physiotherapy for lumbopelvic and low extremities inter-muscular coordination, while the subject group underwent both: physiotherapy for lumbopelvic and low extremities inter-muscular coordination and the functional movement training simultaneously. 
Funkcinių judesių poveikis asmenų, kurie jaučia lètinị nespecifinị apatinès nugaros dalies skausmą, funkcinio liemens pajègumo ir judesio baimès rodikliams

Results. The result analysis before and after the research showed an improvement in all categories evaluated $(p<0.05)$. Pain intensity and functional disability decreased in both groups $(p<0.05)$, however no significant differences were observed between subject and control groups. Kinesiophobia decreased significantly in the experimental group more than in the control group $(p<0.05)$. Significant differences between subject and control groups were observed in trunk functional capacity during stand-to-sit and repeated trunk flexion-extension tasks $(p<0.05)$.

Conclusions. Functional movements combined with lumbopelvic and low extremities inter-muscular coordination exercises reduce kinesiophobia and improve performance of some functional movements more when compared to performing lumbopelvic and low extremities intermuscular coordination exercises alone in patients with chronic nonspecific low back pain

Keywords: functional movements, kinesiophobia, low back pain.

Gautas 20210118

Priimtas 20210413 